\section{Reference}

1 Winter S.C., Thirwell A. \& Jervis P. (2002) Flexible nasendoscope with a disposable-sheath system versus standard nasendoscopy: a prospective, randomized trial. Clin. Otolaryngol. Allied Sci. 27, $81-83$

\title{
Tonsillectomy and residents: a safe match?
}

\section{March 2013}

Sir,

One of the major goals of an Academic Institution is the transmission of knowledge and surgical skills to the residents, without compromising the quality of the service provided to patients. Tonsillectomy is the most common surgical procedure in field of otorhinolaryngology and is one of the first procedures that are taught to residents. Because post-tonsillectomy haemorrhage is potentially life threatening, particularly in children ${ }^{1}$, the assessment of tonsillectomy's safety in resident's hands seems very important.

The aim of our retrospective cohort analysis was to compare the incidence and the risk of complications, for tonsillectomies performed by supervised residents and by senior otolaryngologists. We reviewed the charts of 450 consecutive patients ( 86 under 12 year old and 364 teenagers and adults), who underwent tonsillectomy at our Department, from January 2007 to December 2011. Senior otolaryngologists operated on 274 cases (60.9\%), while 176 patients $(39.1 \%)$ were operated by supervised residents. All procedures were conducted with cold instruments and bipolar hemostasis.
The overall risk of complications and the risk for postoperative bleeding were similar between senior otolaryngologists and supervised residents $(19.34 \%, 21.6 \%$ and $7.66 \%, 5.11 \%$ respectively). The odds ratios for complications are shown in Table 1. Albeit our study highlights that tonsillectomy performed by residents is safe, surprisingly, senior otolaryngologists performed two thirds of the procedures. This scenario has been turned upside down by our new chief.

Tonsillectomy is an easy operation, the surgical field is quite narrow, but still, an experienced otolaryngologist, can effectively supervise the resident performing the procedure. Major bleeding during tonsillectomy is exceedingly rare, but not impossible, and it is usually related to extending the dissection beyond the limit of the pharyngeal muscles, towards the parapharyngeal space. We believe that hot instruments, such as electrocautery, laser and harmonic scalpel, are very effective instruments themselves; and that, in experienced hands, they can be safely used for tonsillectomy; in fact, the intraoperative bleeding is significantly decreased, and the procedure may also easily proceed quicker ${ }^{2}$. On the other hand, hot instruments are not going

Table 1. The risk assessment for complications

\begin{tabular}{|c|c|c|c|c|c|c|}
\hline & \multicolumn{3}{|c|}{ Univariate } & \multicolumn{3}{|c|}{ Multivariate } \\
\hline & $\mathrm{OR}^{\dagger}$ & $95 \% \mathrm{CI}$ & $P$ & $\mathrm{OR}^{\dagger}$ & $95 \% \mathrm{CI}$ & $P$ \\
\hline \multicolumn{7}{|l|}{ Logistic Regression Analysis* } \\
\hline Risk of complications when operated by resident & 0.87 & $0.55-1.39$ & 0.56 & 0.85 & $0.53-1.37$ & 0.51 \\
\hline Risk of fever when operated by resident & 0.58 & $0.27-1.23$ & 0.15 & 0.52 & $0.24-1.15$ & 0.11 \\
\hline Risk of bleeding when operated by resident & 1.50 & $0.69-3.44$ & 0.29 & 1.60 & $0.71-3.61$ & 0.26 \\
\hline \multicolumn{7}{|l|}{ Logistic Regression Analysis in paediatric population* } \\
\hline Risk of complications when operated by resident & 0.52 & $0.17-1.56$ & 0.25 & 0.54 & $0.17-1.71$ & 0.30 \\
\hline Risk of fever when operated by resident & 0.25 & $0.06-1.10$ & 0.07 & 0.16 & $0.03-0.79$ & 0.03 \\
\hline Risk of bleeding when operated by resident & 2.58 & $0.54-12.47$ & 0.24 & 1.58 & $0.7-3.57$ & 0.27 \\
\hline \multicolumn{7}{|l|}{ Logistic Regression Analysis in teenager/adult population* } \\
\hline Risk of complications when operated by resident & 0.98 & $0.58-1.64$ & 0.93 & 0.94 & $0.56-1.60$ & 0.82 \\
\hline Risk of fever when operated by resident & 0.79 & $0.32-1.96$ & 0.61 & 0.79 & $0.31-2.03$ & 0.62 \\
\hline Risk of bleeding when operated by resident & 1.50 & $0.66-3.39$ & 0.33 & 1.54 & $0.68-3.52$ & 0.30 \\
\hline
\end{tabular}

OR, Odds ratio; CI, Confidence interval.

*Adjusted for age, sex, time of operation, American Society of Anesthesiologists physical status classification, Diagnosis.

${ }^{\dagger}$ OR for complications as compared to operation performed by surgeon. Univariate and multivariate model. 
to turn an inexperienced surgeon into an experienced one; conversely, we fear that the relative facility in proceeding with the dissection using hot instruments can lead the inexperienced hand more easily beyond the intended limits of the surgical dissection. In conclusion, according to other studies demonstrating comparable results for total thyroidectomy ${ }^{3}$ and appendectomy ${ }^{4}$, we stated that current practice where residents perform tonsillectomies under supervision should not be disheartened.

\section{Conflict of interest}

None to declare.

\section{References}

1 Kim D.W., Koo J.W., Ahn S.H. et al. (2009) Difference of delayed post-tonsillectomy bleeding between children and adults. Auris Nasus Larynx 37, 456-460

2 Heidemann C.H., Wallen M., Aakesson M. et al. (2009) Posttonsillectomy hemorrhage: assessment of risk factors with special attention to introduction of coblation technique. Eur. Arch. Otorhinolaryngol. 266, 1011-1015

3 Emre A.U., Cakmak G.K., Tascilar O. et al. (2008) Complications of total thyroidectomy performed by surgical residents versus specialist otolaryngologists. Surg. Today 38, 879-885

4 Graat L.J., Bosma E., Roukema J.A. et al. (2012) Appendectomy by residents is Safe and not associated with a higher incidence of complications: a retrospective cohort study. Ann. Surg. 255, 715-719

\author{
Muratori, E., Meccariello, G., Deganello, A., Mannelli, G. \\ \& Gallo, $\mathrm{O}$. \\ Academic Clinic of Otolaryngology and Head-Neck Surgery, \\ University of Florence, Firenze, Italy \\ E-mail: oreste.gallo@unifi.it
}

\title{
Earplugs presenting as an impacted foreign body in the ear canal
}

\section{April 2013}

Sir,

An earplug is inserted in the outer ear canal to protect the user's ears from loud noises or to prevent the intrusion of water, foreign bodies or dust from the surrounding environment. Earplugs are usually made from polyurethane foam, silicone or wax. On occasions due to the effect of body temperature, the wax and silicone earplugs can soften to a dough-like consistency and can become effectively glued to the surrounding ear canal. This complication can result in infection, pain and bleeding in the ear. Removal of such an impacted earplug in the deep external auditory canal (EAC) can be quite challenging and some patients may require general anaesthetic (GA) for this procedure (Table 1).

We would like to raise awareness among otolaryngologists about these issues. Over the last 2 years, we have managed eight patients; three male and five female with a mean age of 36 years (range 24-59 years) who presented with impacted earplugs ( 5 silicone, 2 wax and 1 foam) lodged in the EAC (Fig. 1). While 6 patients had used the ear plugs for blocking

Table 1. Summary of patients with ear plug stuck in the ear

\begin{tabular}{|c|c|c|c|c|c|c|c|c|}
\hline $\begin{array}{l}\text { Serial } \\
\text { number }\end{array}$ & Age & Gender & Side & $\begin{array}{l}\text { Previous } \\
\text { attempt at } \\
\text { plug } \\
\text { removal }\end{array}$ & $\begin{array}{l}\text { GA } \\
\text { needed }\end{array}$ & Type of plug & $\begin{array}{l}\text { Inflammation } \\
\text { of EAC }\end{array}$ & $\begin{array}{l}\text { Topical } \\
\text { antibiotics }\end{array}$ \\
\hline 1. & 24 & F & $\mathrm{R}$ & Yes & No & Foam & Yes & Yes \\
\hline 2. & 25 & M & $\mathrm{R}$ & Yes & No & Silicone & Yes & Yes \\
\hline 3. & 28 & M & $\mathrm{L}$ & Yes & No & Wax & Yes & Yes \\
\hline 4. & 29 & $\mathrm{~F}$ & $\mathrm{~L}$ & Yes & Yes & Silicone & Yes & Yes \\
\hline 5. & 34 & $\mathrm{~F}$ & $\mathrm{~L}$ & Yes & Yes & Silicone & No & No \\
\hline 6. & 35 & M & $\mathrm{R}$ & Yes & No & Silicone & No & No \\
\hline 7. & 56 & $\mathrm{~F}$ & $\mathrm{R}$ & Yes & No & Silicone & No & No \\
\hline 8. & 59 & $\mathrm{~F}$ & $\mathrm{~L}$ & Yes & No & Wax & No & No \\
\hline
\end{tabular}

